\title{
A fully diastereoselective oxidation of a mesoionic dipole with triplet molecular oxygen
}

Received 00th January 20xx, Accepted 00th January 20xx DOI: $10.1039 / \times 0 \times x 00000 x$

\author{
Juan García de la Concepción, ${ }^{\left[{ }^{[a]}\right.}$ Martín Ávalos, ${ }^{[a]}$ José L. Jiménez, ${ }^{[a]}$ Pedro Cintas, ${ }^{[a]}$ and Mark E. \\ Light $^{[b]}$
}

\begin{abstract}
Oxidations with molecular oxygen are ubiquitous processes in biological systems where cofactor-dependent enzymes activate either oxygen or hydrogen peroxide to induce multichannel pathways. In stark contrast, such slow atmospheric oxidations are seldom harnessed in chemical synthesis and analysis. The present study unveils an unusual aerobic oxidation of a mesoionic dipole leading easily to a more functionalized skeleton. Although the synthetic scope has not been explored, two key considerations emerge from this transformation, as it proceeds with complete diastereoselection and could be successfully extrapolated to structurally related mesoionic chirons without racemization. How this oxidation actually occurs proved to be puzzling from the onset and only high-level computation reveals a cascade transformation, whose results reconcile theory and experiment. Hopefully, the mechanistic insights should help us to understand better the autoxidative reactions of organic molecules.
\end{abstract}

\section{Introduction}

Air-induced oxidations of organic compounds, often referred to as autoxidations, play an important role in biosynthetic processes and metabolite degradation. At biological level, such reactions involving the action of molecular oxygen or hydrogen peroxide, are catalyzed by promiscuous enzymes like oxidases, peroxidases or oxygenases, which overcome high-energy barriers under physiological conditions. Although polar and free-radical mechanisms occur, chemistry is a large and complicated issue leading to intermediates such as peroxides and hydroperoxides, which can otherwise evolve to a wide variety of products. ${ }^{1}$ Although atmospheric oxidations under certain conditions can be employed for activating $\mathrm{C}-\mathrm{H}$ bonds and alkenes, ${ }^{2}$ deterioration rather than selective functionalization are common drawbacks with carbo- and heterocyclic systems.

Mesoionic heterocycles, five-membered heterocycles that cannot be represented by Lewis structures without charge separation, have demonstrated to be productive 1,3-dipoles in organic synthesis. ${ }^{3-6}$ In recent years, they have attracted interest as clickable partners in metal-free, strain-activated bioorthogonal couplings oriented to cell visualization. ${ }^{7-9}$ Although mesoionic heterocycles are generally willing dipoles in [3+2]-cycloaddition reactions against unsaturated systems, they lack enough stability in the absence of dipolarophiles and degrade easily. This behavior

\footnotetext{
a. Departamento de Química Orgánica e Inorgánica, Facultad de Ciencias-UEX, and IACYS-Unidad de Química Verde y Desarrollo Sostenible. Avda. Elvas S/N, 06006 Badajoz, Spain.

E-mail: jugarco@unex.es

b. Department of Chemistry, Faculty of Natural and Environmental Sciences, University of Southampton Southampton SO17 1BJ, UK.

† Electronic Supplementary Information (ESI) available: [X-ray diffraction analysis, copies of NMR spectra of all synthetic products, additional computational data and cartesian coordinates for all optimized geometries]. See DOI: 10.1039/x0xx00000x
}

contrasts with that observed for acyclic dipoles, such as thiocarbonyl ylides, which afford 1,4-dithianes through a head-to-head dimerization process. ${ }^{10}$

Accordingly, it was a matter of serendipity to detect the oxidation of an easy-to-make bicyclic mesoionic heterocycle, 5,6dihydrothiazolo[2,3-b]thiazol-4-ium-3-olate (1), allowed to stand with air (triplet oxygen) and leading to a polycyclic derivative with complete stereoselectivity. It is fair to say that photoxidations of some mesoionic rings, namely 1,3-thiazolium-4-olates and 1,3oxazolium-5-olates, were reported in the late 1980 s by Kato et al. ${ }^{11}$ Formation of diacylamides and dehydrodimerization was observed, and the authors suggested cycloaddition of singlet oxygen with the mesoionic ring, affording primarily an endoperoxide followed by fragmentation. Despite some structural similarities with this salient antecedent, the behavior of compound $\mathbf{1}$ exhibited unique features that prompted us to search for a satisfactory rationale. Both experiment and computation-aided studies now provide a sound rationale and a complex picture in line with biomimetic reactions involving oxygenated intermediates.

\section{Results and Discussion}

\section{Atmospheric oxidation and structural insights}

In the course of current investigations dealing with the 1,3-dipolar reactivity of various monocyclic and bicyclic thiazol-3-ium-4-olates, we came across that by storing a solution of dipole $\mathbf{1}^{12}$ in $\mathrm{CH}_{2} \mathrm{Cl}_{2}$ at room temperature for several days, a slow and selective transformation of $\mathbf{1}$ into a pseudo-dimeric compound (2) occurred, which was isolated as a crystalline solid after solvent evaporation (Scheme 1, 34\% yield). This result deviates a priori from the typical messy degradation of the parent mesoionic ring and, as we shall see, 
the structure rather suggests an oxidative coupling as no special precautions were taken to exclude air or moisture.

NMR assignments were instrumental in conjecturing the putative structure of compound 2 . Its ${ }^{13} \mathrm{C}$ NMR spectrum (Fig. S1) was consistent with the presence of three carbonyl groups, three saturated quaternary carbon atoms, and four methylene groups whose diastereotopic hydrogen atoms gave rise to eight different signals in the corresponding ${ }^{1} \mathrm{H}$ NMR spectrum (Fig. S2). The existence of two phenyl groups could be inferred from such spectra as well. The analysis of homo- and heteronuclear correlation spectra of 2 allowed us to corroborate the assignment of both ${ }^{1} \mathrm{H}$ and ${ }^{13} \mathrm{C}$ resonances (Figs. S3 and S4). Then, suitable monocrystals of $\mathbf{2}$ for its $\mathrm{X}$-ray diffraction analysis, could be obtained by slow evaporation from a $\mathrm{CH}_{2} \mathrm{Cl}_{2}$-ethyl acetate solution. The resulting structure showed the relative stereochemistry of all substituents and, notably, the existence of an additional oxygen atom with respect to the true stoichiometric dimer (Fig. 1).

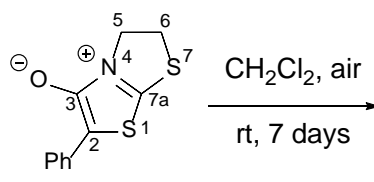

1

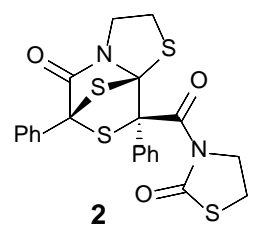

Scheme 1 Spontaneous synthesis of 2 (34\% yield) from 2-phenyl-5,6dihydrothiazolo[2,3-b]thiazol-4-ium-3-olate (1).

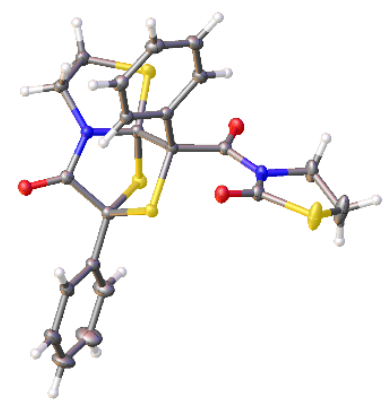

Fig. 1 ORTEP plot (thermal ellipsoids at the $50 \%$ probability) of the single-crystal structure of compound $\mathbf{2}$.

When the reaction was carried out in dry non-degassed $\mathrm{CH}_{2} \mathrm{Cl}_{2}$, identical results were obtained, whereas under an argon atmosphere, the reaction slowed down and compound $\mathbf{2}$ started to form after ca. 4 days (we conjectured that formation of $\mathbf{2}$ occurred on exposure to air when aliquots were taken for reaction monitoring).

In order to ascertain if the reaction was light-sensitive, it was also conducted in absolute darkness by carefully wrapping the vessel with aluminum foil and storing the mixture in a dark place. A parallel protocol was performed by irradiating the reaction flask with a UV lamp (at 370 and $254 \mathrm{~nm}$ ). However, both experiments gave identical results to those mentioned above.

The isolated yield of $\mathbf{2}$ increased and the reaction time was reduced to 5 days by increasing the concentration of 1 or, alternatively by passing an air stream through the solution (see Experimental section, 84 and $80 \%$ yields, respectively). A retrosynthetic analysis suggests that $\mathbf{2}$ could be generated through a regio- and stereoselective 1,3-dipolar cycloaddition of 1 with the thiocarbonyl group of 3-(2-phenyl-2-thioxoacetyl)thiazolidine-2-one (3) (Scheme 2).

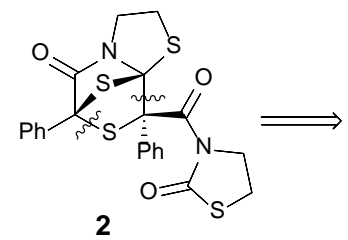

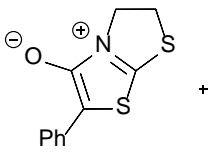

1<smiles>O=C1SCCN1C(=O)C(=S)c1ccccc1</smiles>

3
Scheme $\mathbf{2}$ Retrosynthetic analysis of $\mathbf{2}$.

Chemical evolution of 1 was noticeable after 5 days as evidenced by ${ }^{1} \mathrm{H}$ NMR monitoring (see Fig. 2 and Fig. S5). Fig. 2 shows an eyecatching spectrum where only three signal sets were observed, attributable to the mesoionic heterocycle 1, the newly generated pseudo-dimer $\mathbf{2}$, and a third compound, as a by-product, showing in addition three deshielded signals in the ${ }^{13} \mathrm{C}$ NMR spectrum (Fig. S6), initially assigned to (thio)carbonyl groups of 3. Peak integration evidenced a 1:1 ratio for the latter and $\mathbf{2}$. However, as we will discuss below, the structure initially proposed for $\mathbf{3}$ actually corresponds to 1-phenyl-2-(2-thioxothiazolidin-3-yl)ethane-1,2-dione (4).

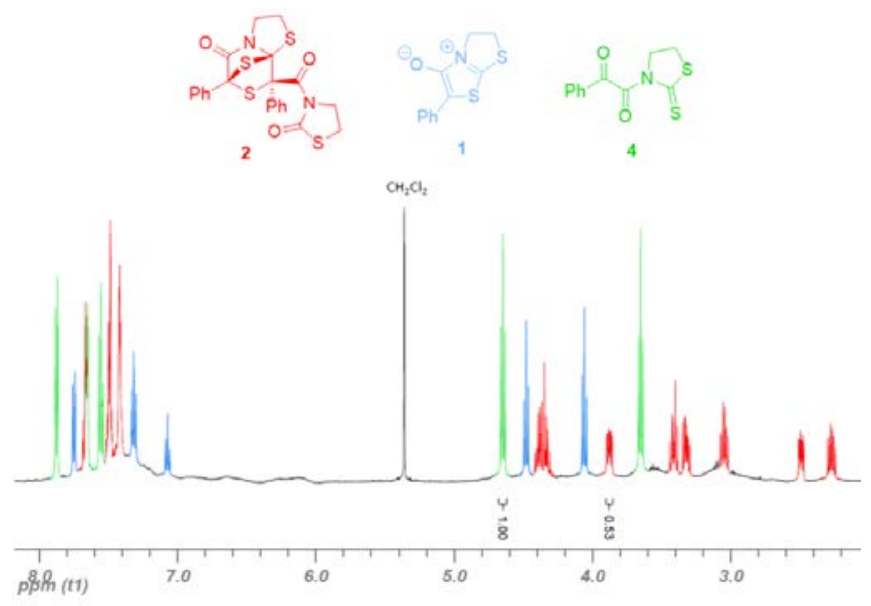

Fig. $2{ }^{1} \mathrm{H} \mathrm{NMR}\left(\mathrm{CDCl}_{3}, 500 \mathrm{MHz}\right)$ of the crude mixture of $\mathbf{1}$ (green), $\mathbf{2}$ (blue), and 4 (red) in $\mathrm{CH}_{2} \mathrm{Cl}_{2}$.

\section{Preliminary understanding from first-principle calculations}

Bearing in mind that dipole 1 is oxidized by molecular oxygen to give 2 and the thiocarbonyl by-product, additional oxidation experiments were carried out by mixing 1 with $m$-chloroperbenzoic acid $(m$ (PBA). A mixture of 1 and $m$-CPBA was stirred for $10 \mathrm{~h}$ in dry $\mathrm{CH}_{2} \mathrm{Cl}_{2}$. Under these conditions compound $\mathbf{4}$ could be isolated indeed, but neither $\mathbf{2}$ nor $\mathbf{3}$ were detected at all. Before going further, theory could be of help and in order to get a deeper insight, we computed the reaction pathways when $m$-CPBA approaches both the $C 2$ and $\mathrm{C} 7 \mathrm{a}$ atoms of the dipole $\mathbf{1}\left(\mathrm{TS}_{m \text {-CPBA }} \mathbf{C 2}\right.$ and $\mathrm{TS}_{m \text {-CPBA }} \mathrm{C7a}$ respectively) at the (U)B3LYP-D3BJ/def2-TZVP level of theory in $\mathrm{CH}_{2} \mathrm{Cl}_{2}$ (SMD). ${ }^{13-16}$ The attack of $m$-CPBA to $\mathrm{C} 2$ gives rise to 4 while at C7a affords 3 , in a concerted manner as inferred from the intrinsic reaction coordinate (IRC) analyses. Free energy values of these saddle points show that the approach to $\mathrm{C} 2$ is favored by $8.4 \mathrm{kcal} \mathrm{mol}^{-1}$, pointing to a selective 
formation of dithiocarbamate 4 (see Fig. S7 and S8 with further explanation of the reaction).

An experimental confirmation supporting the formation of 4 , and not $\mathbf{3}$, during the autoxidation of $\mathbf{1}$ was obtained by reacting dipole $\mathbf{1}$ with the product resulting from 1 and $m$-CPBA under several conditions (see experimental section). Neither pseudo-dimer $\mathbf{2}$ nor other reaction product could be detected. This finding rules out the formation of thioketone $\mathbf{3}$ as the thiocarbonyl derivative, because the latter would react easily with $\mathbf{1}$ to give $\mathbf{2}$ through a dipolar cycloaddition, consistent with the low free energy barrier found for such reaction (Fig. S9). This experiment clearly discards the possibility of a dipolar cycloaddition involving dipole 1.

On the other hand, a calculation of the shielding tensors of $\mathbf{3}$ and 4 using the Gauge-Independent Atomic Orbital method (GIAO) ${ }^{17}$ and their comparison with the experimental chemical shifts (recorded in $\mathrm{CDCl}_{3}$ ) reveal that the best correlation corresponds to both theoretical and experimental chemical shifts of 4 (Fig. S10).

\section{Reaction mechanism: intersystem crossing}

At this stage, a few experimental data show a clear-cut reaction portrait; i.e. the mesoionic heterocycle 1 oxidizes with molecular oxygen present in air to give the pseudo dimer $\mathbf{2}$ along with dithiocarbamate $\mathbf{4}$, and the reaction rate increases as concentration does. The first point to take into account is that oxygen is a triplet diradical $\left({ }^{3} \mathrm{O}_{2}\right)$ in its ground state, while the final product is a pure singlet. Thus, there must be an intersystem crossing (ISC) during the reaction pathway.

In the beginning of the chemical reaction there are four competitive pathways: the addition of ${ }^{3} \mathrm{O}_{2}$ to $\mathrm{C} 2\left({ }^{3} \mathrm{TS} 1_{\mathrm{C} 2}\right)$ and $\mathrm{C} 7 \mathrm{a}$ ${ }^{3} \mathrm{TS1}_{\mathrm{C7a}}$ ) of 1 together with the reaction between two units of 1 , i. e. the approaches of $\mathrm{Si}-\mathrm{C} 2$ and $\mathrm{Re}-\mathrm{C} 2$ of $\mathbf{1}$ to the $\mathrm{C} 7 \mathrm{a}$ of the other unit of $\mathbf{1}\left(\mathbf{T S}_{1-1} \mathbf{a}\right.$ and $\mathbf{T S}_{1-1} \mathbf{b}$, respectively). Computation shows that the addition of ${ }^{3} \mathrm{O}_{2}$ to the $\mathrm{C} 7$ a of 1 , leading to ${ }^{3}$ Int1, is the most favorable process (orange profile in Fig. 3). Due to the diradical character of the triplet states ${ }^{3} \mathrm{TS} 1_{\mathrm{C7a}}$ and ${ }^{3}$ Int1 $\left\langle\left\langle S^{2}\right\rangle=2.03\right.$ and $\left\langle S^{2}\right\rangle=2.02$, respectively), we also calculated these stationary points in open-shell singlet state $\left({ }^{1} \mathrm{TS} 1_{\mathrm{Cza}}\right.$ and ${ }^{1}$ Int1, black free energy profile in Fig. 3 ). Although the free energy differences between the singlet and triplet states are small, the formation of ${ }^{\mathbf{3}}$ Int1 is still the most favorable route.

The high energy of ${ }^{3} \mathbf{T S} 1_{\mathrm{C} 2}$ with respect to ${ }^{3} \mathrm{TS} 1_{\mathrm{C7a}}$ can be attributed to the high distortion of the dipole at the saddle point as viewed in Fig. 4. An NBO analysis of the alpha orbitals in C2 and C7a for ${ }^{3} \mathrm{TS} 1_{\mathrm{C} 7 \mathrm{a}}$ and ${ }^{3} \mathrm{TS} 1_{\mathrm{C} 2}$, respectively, shows that the unpaired electron of $\mathrm{C} 2$ in ${ }^{3} \mathrm{TS} 1_{\mathrm{C} 7 \mathrm{a}}$ is located in a $\pi$ orbital, which is delocalized with the phenyl ring and the $\pi^{*}$ (C3-O) of the carbonyl group. The global effect, i.e. unpaired electron essentially delocalized with the phenyl and the carbonyl group as well, forces the dipole to acquire a planar geometry. Furthermore, the unpaired alpha electron of $\mathrm{C} 7 \mathrm{a}$ in ${ }^{3} \mathrm{TS} 1_{\mathrm{C} 2}$ is placed in an atomic $p$-type orbital, which lacks delocalization and distorts its geometry to move the two unpaired electrons away from each other, thereby alleviating the Coulomb repulsion (Fig. 4).

An alternative and plausible pathway that cannot be excluded a priori would involve the oxidation by molecular oxygen of the mesoionic dipole leading to a radical cation, which might then be stabilized by sulfur and nitrogen atoms, with the concomitant reduction of oxygen into superoxide anion. However, by computing this surmise with solvent-based calculation, the energy of the resulting system with respect to 1 and ${ }^{3} \mathrm{O}_{2}$ is exceedingly higher $(\Delta E$
$=47.8 ; \Delta G=47.3 \mathrm{kcal} \mathrm{mol}^{-1}$ ), thereby suggesting that such species cannot reach these electronic states under the experimental conditions. Thus, the search for a plausible mechanism involves the evolution of the triplet intermediate ${ }^{3}$ Int1.

To ascertain if there is an intersystem crossing between the two potential energy surfaces (PESs), namely formation of ${ }^{3}$ Int1 and ${ }^{1}$ Int1, two scans were calculated by varying the degree of freedom around $\mathrm{C} 7 \mathrm{a}-\mathrm{O}$ for the two electronic states. Also, for both stationary points $\left({ }^{1} \mathbf{T S} 1_{\mathrm{CZa}}\right.$ and $\left.{ }^{1} \mathbf{I n t} \mathbf{1}\right)$ and the fully scanned PES of the singlet

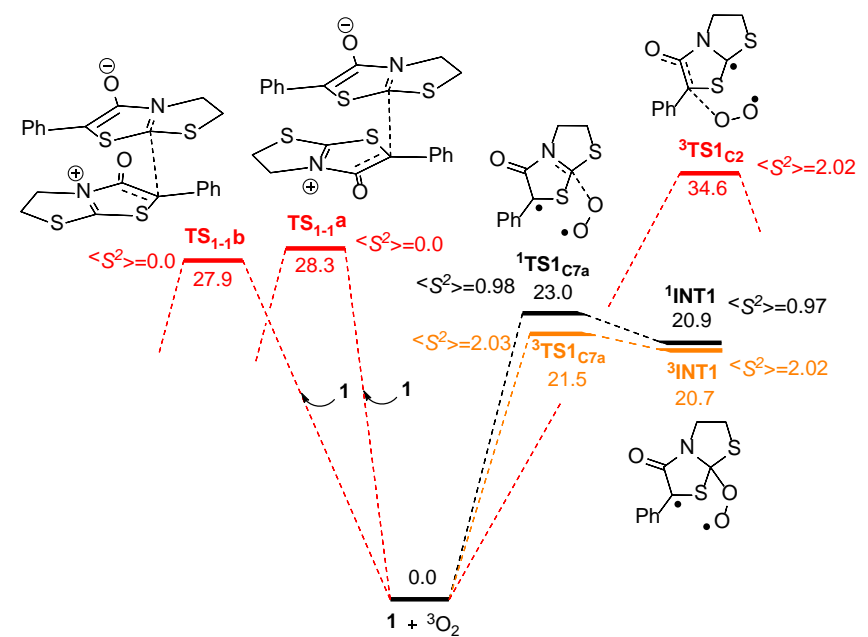

Fig. 3 Free energy profiles for the initial competitive reactions between ${ }^{3} \mathrm{O}_{2}$ and $\mathbf{1}\left({ }^{3} \mathrm{TS}_{\mathrm{C2}}\right.$ and $\left.{ }^{3} \mathrm{TS} 1_{\mathrm{C7a}}\right)$ and two units of $\mathbf{1}\left(\mathrm{TS}_{1-1} \mathbf{a}\right.$ and $\mathrm{TS}_{1-1} \mathbf{b}$ ) at (U)B3LYP-D3BJ/def2-TZVP in $\mathrm{CH}_{2} \mathrm{Cl}_{2}$ (SMD). The relative free energies are given with respect to dipole 1 and ${ }^{3} \mathrm{O}_{2}$ in $\mathrm{kcal} \mathrm{mol}^{-1}$. Eigenvalues of the total spin operator $\left[\left\langle S^{2}\right\rangle\right]$ are given without the spin annihilation diagnostic.
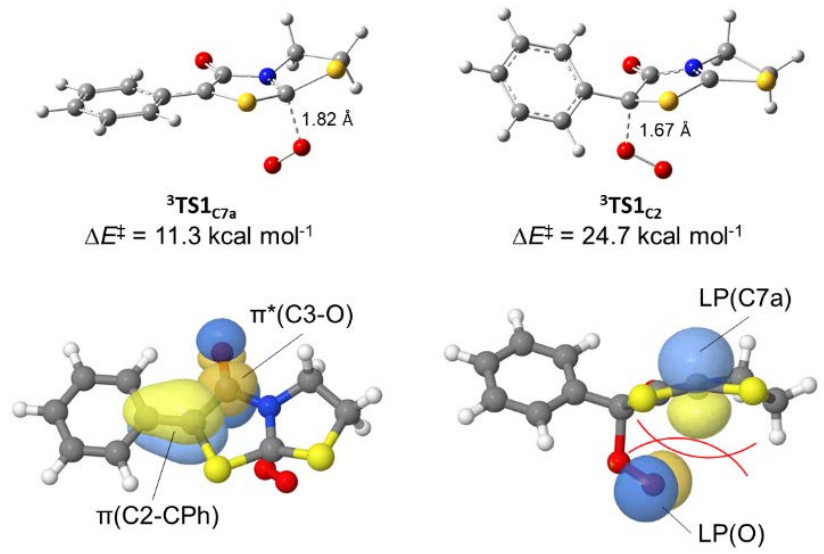

Fig. 4 Optimized geometries of ${ }^{3} \mathrm{TS} 1_{\mathrm{C} 2}$ and ${ }^{3} \mathrm{TS} 1_{\mathrm{C} 7 a}$ at (U)B3LYPD3BJ/def2-TZVP in $\mathrm{CH}_{2} \mathrm{Cl}_{2}$ (SMD) (above). Relative electronic energies are given with respect to 1 and ${ }^{3} \mathrm{O}_{2}$ in $\mathrm{kcal} \mathrm{mol}^{-1}$. Alpha NBO orbitals are computed at the same level of theory and depicted below.

state, we calculated the broken-symmetry wavefunctions [BS(U)DFT] in order to destroy the $\alpha-\beta$ spatial symmetries. These calculations led to a mixture of singlet and triplet states where the $\alpha$ and $\beta$ orbitals are non-degenerated and the values of the total spin operator $\left\langle S^{2}\right\rangle$ are very close to 1 , i.e. singlet diradicals. The whole triplet pathway is lower in energy than the singlet, and there is not 
crossing between the two PESs. However, when the systems get closer to the energy minimum Int1, the energy differences between the potential energy surfaces become shorter, almost degenerate (Fig. S 11).

Due to the small energy gap and the structural similarity between ${ }^{1}$ Int1 and ${ }^{3}$ Int1, a minimum energy crossing point (MECP) optimization was performed through the Harvey's method starting from the ${ }^{3}$ Int1 structure. ${ }^{18}$ The MECP geometry is almost the same as those of ${ }^{1}$ Int1 and ${ }^{3}$ Int1 (Fig. 5). The most important geometrical difference among the three structures is the dihedral angle O-O-C7aN8, being -55.60 , $-49.2^{\circ}$ and $-38.3^{\circ}$ for ${ }^{3}$ Int1, MECP and ${ }^{1}$ Int1, respectively. Since this degree of freedom seems to be a key feature in the intersystem crossing, we also computed PES scans varying the above dihedral angle for the two Int1 (Fig. 6). In this case, we found a crossing point between the two surfaces that matches almost exactly with the MECP optimized geometry. Owing to the multireference character of these systems and to explore the validity of the (U)DFT calculations, single point energies of the previously optimized singlet and triplet critical points TSC $_{7 a}$, Int1, and MECP were also calculated at the complete active space self-consistent method (CASSCF) ${ }^{19}$ with a $(8,8)$ active space (see Fig. S11 for further details). Although (U)DFT and CASSCF energy differences are not fully coincidental, such data are similar enough to qualitatively ensure that the energy differences between these states are pretty short and the triplet PES is always more stable as evidenced by the energy differences, regardless of the method employed (for further details on the selection of the active space, see Computational details).

Since the crossing yield of two spin states depends mainly on the energy required for the system to reach a configuration where the potential energy is quite close for these spin states, and/or on a high magnitude of spin-orbit coupling (SOC) between the two spin states; the corresponding SOC constants for the three critical points of our PESs from the ground states (triplet) to the first excited state (singlet) were calculated as well. Computations were carried out at the stateaverage CAS (SA-CASSCF) with the $(8,8)$ active space having equal weights for the different states. SOC constant values are quite small in the three cases $\left(0.6,0.1\right.$ and $0.2 \mathrm{~cm}^{-1}$ for ${ }^{3} \mathrm{TSC}_{7 \mathrm{a}},{ }^{3}$ Int1 and MECP, respectively), thus pointing to a small coupling between these PESs. This can be interpreted by the absence of change in the orbital angular momentum between the two spin states, being the transition orbital the $\pi^{*}(0-0)$ for the three critical points (see the configuration of the active space for ${ }^{3} \mathrm{TSC}_{7 \mathrm{a}},{ }^{3} \mathrm{Int} \mathbf{1}$ and MECP in Fig. S11). Similar cases with small singlet-triplet SOC due to the lack of change in orbital angular momentum have been recently reported for reactions of $\mathrm{O}\left({ }^{3} \mathrm{P}\right)$ with alkylamines. ${ }^{20}$ Although this coupling is small indeed, the transition probabilities between the two PESs are high, as going from ${ }^{3}$ Int1 to MECP there should be a turn in the O-OC7a-N8 angle of 6.4을 which merely involves an energy gap of just $0.15 \mathrm{kcal} \mathrm{mol}^{-1}$ [ $\Delta E$ (MECP - ${ }^{3}$ Int1)]. This feature has also been detected in other reactions with molecular oxygen, where such dihedral angle variations constitute the key element of the ISC. ${ }^{21}$
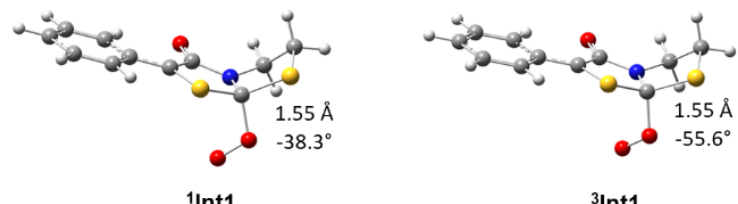

$\Delta E^{\ddagger}=10.1 \mathrm{kcal} \mathrm{mol}^{-1}$ $\Delta E^{\ddagger}=10.0 \mathrm{kcal} \mathrm{mol}^{-1}$

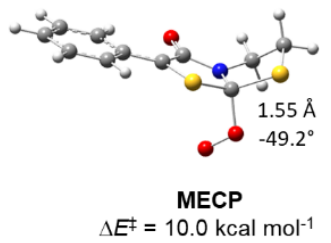

Fig. 5 Optimized geometries of ${ }^{1}$ Int1, ${ }^{3}$ Int1 and MECP at (U)B3LYPD3BJ/def2-TZVP in $\mathrm{CH}_{2} \mathrm{Cl}_{2}$ (SMD). Relative electronic energies are given with respect to 1 and ${ }^{3} \mathrm{O}_{2}$ in $\mathrm{kcal} \mathrm{mol}^{-1}$. Bond distances (C7a-O) and dihedral (O-O-C7a-N4) angles are given in angstrom and degrees respectively.

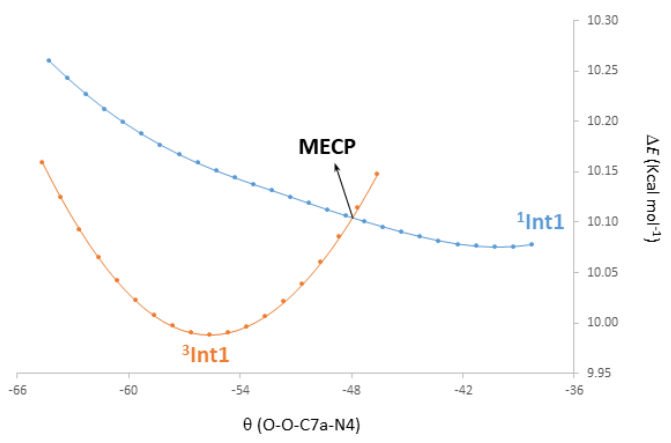

Fig. 6 Scan PESs for the ${ }^{1}$ Int1 and ${ }^{3}$ Int1 varying the diedral angle O-OC7a-N5 computed at (U)B3LYP-D3BJ/def2-TZVP in $\mathrm{CH}_{2} \mathrm{Cl}_{2}$ (SMD). The whole singlet pathway is computed at the broken symmetry (U)DFT. 




TS2

$\Delta E^{\ddagger}=11.4 \mathrm{kcal} \mathrm{mol}^{-1}$ $\Delta G^{\ddagger}=23.9 \mathrm{kcal} \mathrm{mol}^{-1}$ $\left\langle S^{2}\right\rangle=0.54$

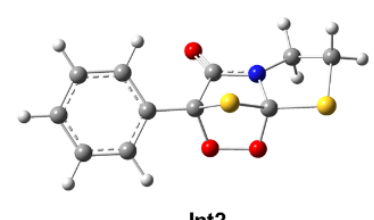

Int2
$\Delta E^{\ddagger}=-13.0 \mathrm{kcal} \mathrm{mol}^{-1}$
$\Delta G^{\ddagger}=1.3 \mathrm{kcal} \mathrm{mol}^{-1}$ $\begin{aligned} \Delta G^{\ddagger} & =1.3 \mathrm{kcal} \mathrm{mo} \\ \left\langle S^{2}\right\rangle & =0.00\end{aligned}$



Fig. 7 Optimized geometry of TS2 and Int2 at (U)B3LYP-D3BJ/def2TZVP level in $\mathrm{CH}_{2} \mathrm{Cl}_{2}$ (SMD). Spin density iso-surface of TS2 is given with a density isovalue of 0.005 (bottom). Scan of the PES connecting ${ }^{1}$ Int1 and Int2 (blue curve) and $\left\langle S^{2}\right\rangle$ values during the scan (purple curve) are shown. Relative electronic and free energies are given with respect to 1 and ${ }^{3} \mathrm{O}_{2}$ in $\mathrm{kcal} \mathrm{mol}^{-1}$. Eigenvalues of the total spin operator $\left[\left\langle S^{2}\right\rangle\right]$ are given without the spin annihilation diagnostic.

Once the system has reached the singlet PES at MECP, it cyclizes easily to the peroxide Int2 across TS2 (blue profile in Fig. 7) through a very small energy barrier $\left[\Delta E\left(T_{S 2}-{ }^{1} \operatorname{Int} 1\right)=1.3 ; \Delta \mathrm{G}\left(\mathbf{T S 2}-{ }^{-1} \operatorname{Int} \mathbf{1}\right)=3.0\right.$ $\left.\mathrm{kcal} \mathrm{mol}{ }^{-1}\right]$. The $\left\langle S^{2}\right\rangle$ value during the variation of the $\mathrm{C} 2-\mathrm{O}$ coordinate (purple line in Fig. 7) shows that the spin density is lost after passing immediately the TS2. However, spin density still remains in the saddle point TS2 with a value of $\left\langle S^{2}\right\rangle=0.54$ (Fig. 9, bottom). This value indicates that TS2 is neither a pure singlet diradical $\left(\left\langle S^{2}\right\rangle=1\right)$ nor a pure singlet $\left(\left\langle S^{2}\right\rangle=0\right)$, because the two $\alpha$ and $\beta$ unpaired electrons approach each other for ring closure and the $\alpha$ and $\beta$ orbitals loose the non-degeneracy. From this point (Int2) onwards, the system remains in its pure singlet state until the reaction reaches the products ( $\mathbf{2}$ and $\mathbf{4})$, where all the stationary points show a value of $\left\langle S^{2}\right\rangle=0.0$.

The peroxide Int2 could then evolve through two different pathways, both leading to the S-oxide of dipole $\mathbf{1}(\operatorname{Int} 3)$ and two thiocarbonyl compounds (3 and 4 ). In both pathways dioxirane species (Int4 and Int5) are formed and constitute the ratedetermining steps. However, the most favored pathway leads to the experimentally detected dithiocarbamate 4 while the less favored routes lead to thioketone $\mathbf{3}$ (see Scheme 3 as simplified diagram and Fig. 8 for a detailed mechanistic description).

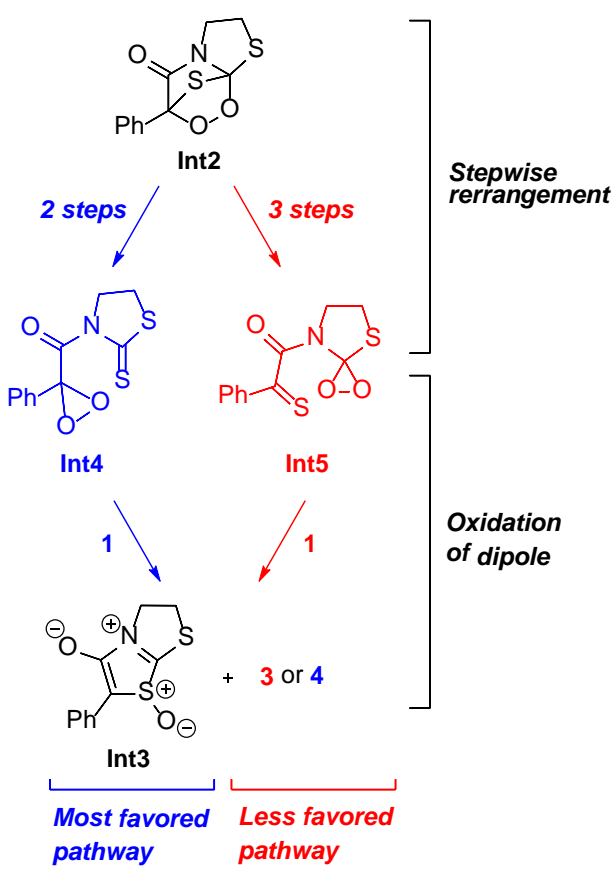

Scheme 3 Evolution of Int2 to give Int3. 



Fig. 8 Free energy pathways leading to the S-oxide Int3 from the MECP. Energy data are relative free energies with respect to 1 and ${ }^{3} \mathrm{O}_{2}$ in $\mathrm{kcal} \mathrm{mol}^{-1}$. $\mathbf{s}$ and $\mathbf{t}$ energy values are relative free energies of the singlet and triplet configurations, respectively, of the MECP.

The most favored pathway oxidizes 1 to give Int3 and 4 . It is pertinent to point out that all attempts to find a pathway involving homo and/or heterolytic breaking of the O-O bond of the peroxide gave inconsistent results. The less favored pathway starts breaking the S-bridge of the adduct (TS3b) to afford a zwitterionic intermediate (Int3b), which evolves into the complex Int4b where the O-C2 interaction is not a real bond, but an electrostatic interaction. The latter isomerizes to dioxirane Int5 through the transition structure $\mathbf{T S} \mathbf{5} \mathbf{b}$, which is the rate-determining step of the whole reaction pathway. Dioxirane Int5 oxidizes then a molecule of compound $\mathbf{1}$ to give the highly stable thioketone $\mathbf{3}$ and the S-oxide Int3. On the other hand, the most favored pathway involves the rearrangement of Int2 giving rise to the carbonyl oxide Int3a, where the bonds S-bridge-C2 and O-C7a fragment simultaneously through TS3a. We hypothesized that the 1,3-dipole Int3a could react with 1; however all attempts to locate this pathway were unsuccessful. Moreover, it was found that isomerization of Int3a to the dioxirane Int4 through TS4a was the rate-determining step of this reaction. Like the less favorable route, the dioxirane Int4 oxidizes dipole 1 leading to the S-oxide Int3 and the experimentally-detected dithiocarbamate 4.

The last part of the mechanism involves the reaction of Int3 with an additional molecule of $\mathbf{1}$ (Fig. 9). Note that for Int3 the sulfur atom, which acts as $\pi$ spacer of the dipole, becomes chiral when it abstracts an oxygen atom. Thus, when Int5 approaches dipole 1, there are four reaction channels that could lead to the pseudodimer $\mathbf{2}$ or to its diastereomer $\mathbf{2 b}$. Among all competitive processes, the one affording the experimentally detected pseudo-dimer 2 becomes the most favored transformation.

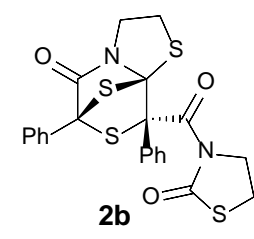

When the Re-face of C7a of Int3 approaches dipole 1, there are four reaction channels, namely the approaches to the $\mathrm{Si}$-face of $\mathrm{C} 2$ of 1 having $R$ and $S$ configurations at S1 (TS6a and TS6b, respectively) and the approaches to the $R e$-face of $\mathrm{C} 2$ of 1 , having $R$ and $S$ configurations at S1 too (TS6c and TS6d, respectively). For TS6a and TS6c the oxygen linked to S1 is close to 1 while for TS6b and TS6d it is far from the dipole partner. As expected, TS6b and TS6d are favored due to the reduction of steric interaction exerted by the oxygen atom attached to sulfur. Next step involves the oxygen transfer from sulfur to the C7a of 1 (TS7). For this step to occur the oxygen must be close to the C7a of 1 and if the system evolves to Int6b and Int6d, the chiral sulfur must epimerize to reach Int6a and Int6c (TSb rac $_{\text {and }}$ TS $\mathbf{d}_{\text {rar }}$ ).

However, these epimerization reactions show towering free energy barriers that cannot be overcome. Contrary to the umbrella effect in amines, this reaction cannot undergo any tunneling effect due to the low imaginary frequency of the saddle points $\left(\bar{U}_{1}=\right.$

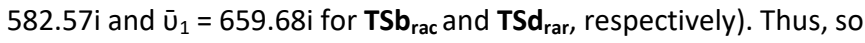
long as the reaction moves forwards, Int6a and/or Int6c must be formed. Formation of Int6a is favored by $3.9 \mathrm{kcal} \mathrm{mol}^{-1}\left[\left[\Delta \Delta G^{\ddagger}\right.\right.$ (TS6c - TS6a)], thereby justifying the formation of $\mathbf{2}$ (which arises from Int6a) instead of $\mathbf{2 b}$, which would come from Int6c.

It is noteworthy the structural similarity of saddle points TS6a-c $\left(\mathbf{1}+\right.$ Int3) and $\mathrm{TS}_{\mathbf{1 - 1}} \mathbf{a}-\mathbf{b}(\mathbf{1}+\mathbf{1}$, Fig. 3), which differ however by significant energy heights (Table S1). A plausible explanation 


\section{ARTICLE}

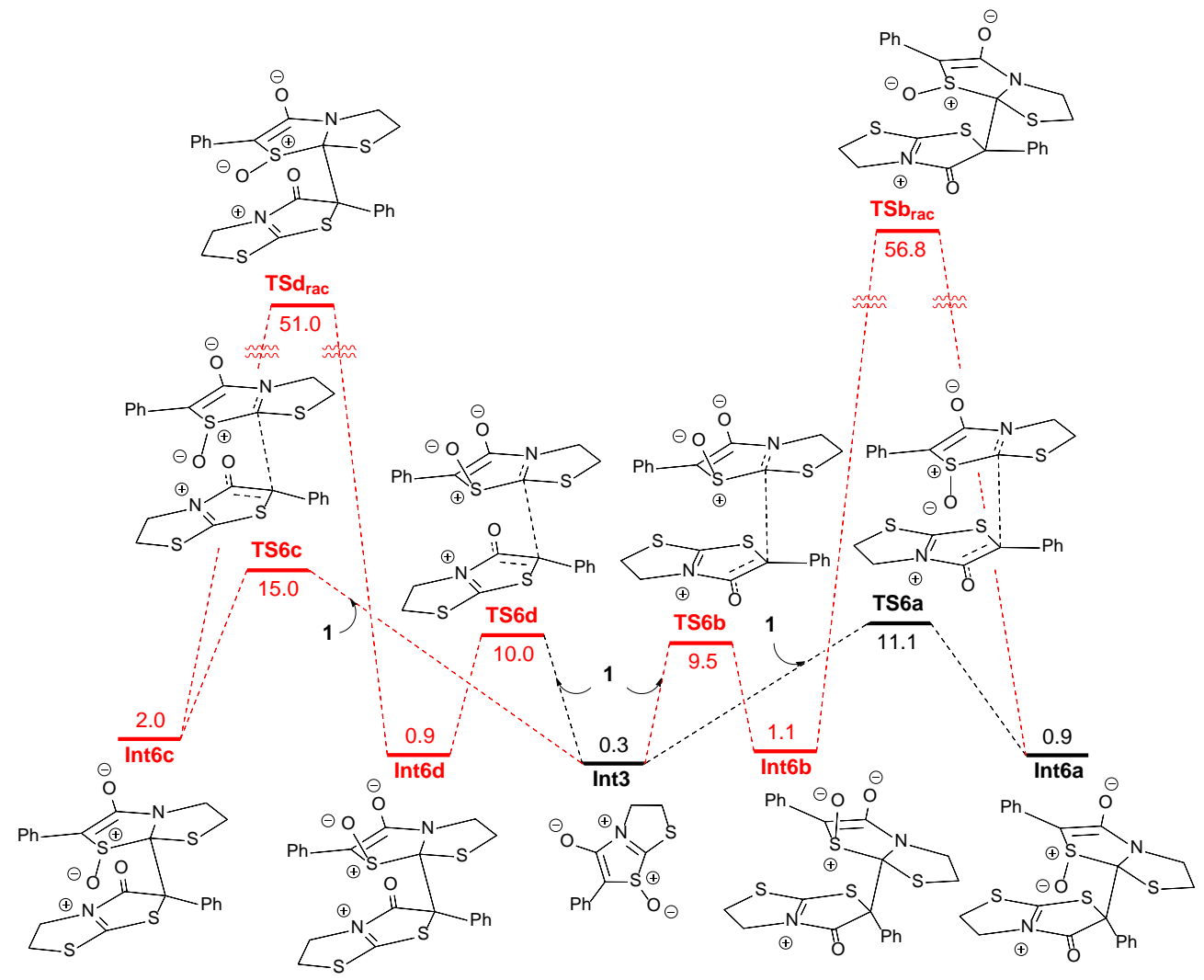

Fig. 9 Free energy pathways of the four competitive approaches of $\mathbf{1}$ to Int3, and evolution of Int6a leading to the pseudo-dimer $\mathbf{2}$. Energy data are relative free energies with respect to 1 and ${ }^{3} \mathrm{O}_{2}$ in kcal mol${ }^{-1}$.

accounting for the difference in reactivity can be obtained by examining the FMOs of both compounds. The shape and energy gap of the FMOs not only indicate that TS6 involves the most favorable interaction, but also justify the coupling between C7a of Int3 with C2 of 1 (Fig. S12).

The last step is the electrophilic attack of the $\mathrm{C} 2$ to the vicinal sulfur atom, affording a new carbonyl group and yielding the highly stable pseudo-dimer $\mathbf{2}$ through TS8 (Fig. 10). This saddle point is very close in energy to the previous intermediate Int7 owing to their almost identical structures, which translates into similar frequencies as evidenced by zero point energy differences $\left[\Delta \triangle E+E_{Z P E}(\right.$ TS8 - Int7) $\left.=0.04 \mathrm{kcal} \mathrm{mol}^{-1}\right]$.

The full free energy landscape depicted in Fig. 10 provides a rationale for the autoxidation of the mesoionic dipole 1 with triplet molecular oxygen. With such a picture, one can likewise justify the higher rate at a higher concentration, since intermediates such as Int3 and Int4 will be able to collide with more units of $\mathbf{1}$ to reach the final products with the concomitant formation of $\mathbf{4}$ and $\mathbf{2}$ in 1:1 ratio. The stoichiometry is shown in Scheme 4. 


\section{ARTICLE}

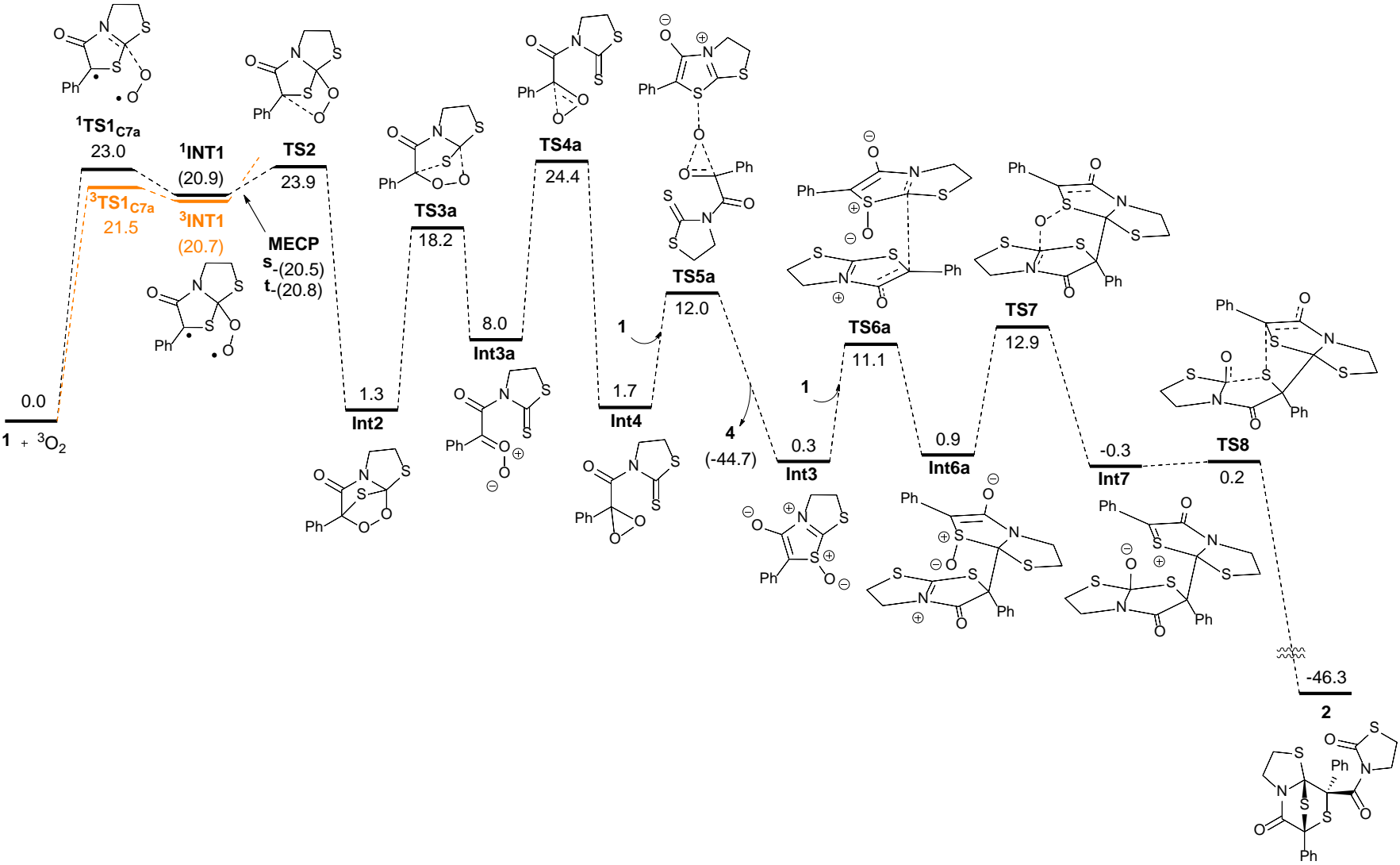

Fig. 10 Full free energy profile for the autoxidation of $\mathbf{1}$ leading to $\mathbf{2}$ and $\mathbf{4}$, as calculated at (U)B3LYP-D3BJ/def2-TZVP level in CH${ }_{2} \mathrm{Cl}_{2}$ (SMD) in $\mathrm{kcal} \mathrm{mol}^{-1}$. $\mathbf{s}$ and $\mathbf{t}$ energy values are relative free energies of the singlet and triplet configurations, respectively, of the MECP.<smiles>O=[N+]([O-])[O-]</smiles>

1
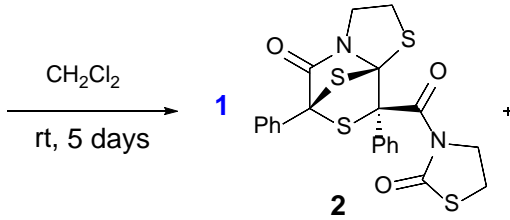<smiles>O=C(C(=O)N1CCSC1=S)c1ccccc1</smiles>

4

Scheme 4 Reaction stoichiometry for the autoxidation of dipole 1 yielding the pseudo-dimer $\mathbf{2}$ and dithiocarbamate 4.

\section{Synthesis of enantiomerically pure pseudo-dimers}

Encouraged by the stereochemical outcome of this transformation of mesoionic $\mathbf{1}$, we checked further the synthetic protocol with two chiral derivatives, namely heterocycles $\mathbf{5}$ and $\mathbf{6}$ bearing side isopropyl and phenyl groups, respectively, which could then lead to enantiomerically pure and highly functionalized pseudodimers. Even though the sequential reaction was as sluggish as that of 2, polycycles $\mathbf{7}$ and $\mathbf{8}$, resulting from the autoxidation of dipoles $\mathbf{5}$ and $\mathbf{6}$, were isolated in crystalline form (Scheme 5). Gratifyingly, their structures could be unambiguously determined by X-ray diffractometry (Fig. 11).

The formation of $\mathbf{7}$ and $\mathbf{8}$ appears to be completely diastereoselective, although the $i \mathrm{Pr}$ and $\mathrm{Ph}$ groups of the parent dipoles, 5 and $\mathbf{6}$, respectively, do not induce any notable facial stereoselection when reacting with triplet oxygen, as evidenced by the low free energy differences of the two reaction channels, i.e. when ${ }^{3} \mathrm{O}_{2}$ approaches the $\mathrm{C} 7 \mathrm{a}-\mathrm{Si}$ and $\mathrm{C} 7 \mathrm{a}-\mathrm{Re}$ faces of the dipoles. (Fig. S31). This deviates from the high facial stereoselection observed for 5 against bulky dipolarophiles. ${ }^{12}$ On the other hand, the key step in 
the stereoselective formation of $\mathbf{7}$ and $\mathbf{8}$ should clearly depend on transition structures equivalent to TS6a (Fig. 10).

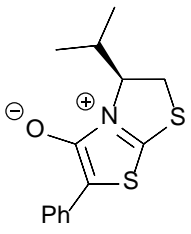

5

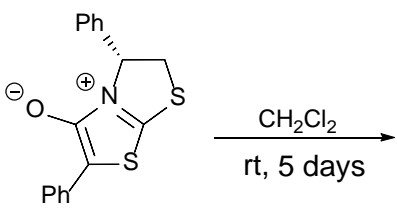

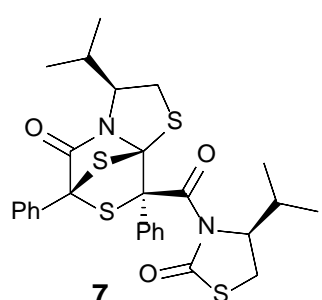

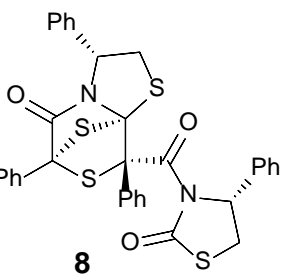

Scheme 5 Autoxidation of chiral dipoles 5 and $\mathbf{6}$ to give the homochiral polycycles $\mathbf{7}$ and $\mathbf{8}$.
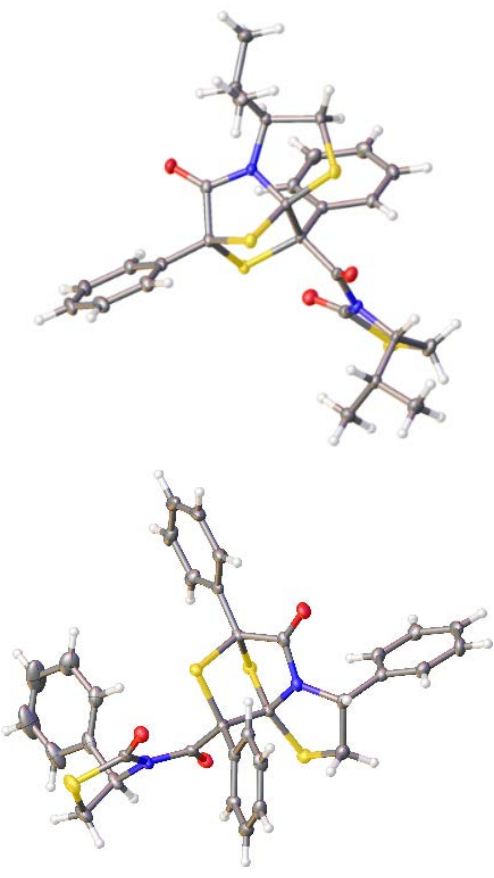

Fig. 11 ORTEP plots (thermal ellipsoids at the $50 \%$ probability) of the single-crystal structures of compounds $\mathbf{7}$ (left) and $\mathbf{8}$ (right).

\section{Conclusions}

This work documents a valuable chemical transformation of a bicyclic mesoionic heterocycle into a complex pseudo-dimer coming from aerobic oxidation with triplet oxygen. The multifaceted mechanism has been validated by experimental observations and supported by computational studies. A retrosynthetic analysis suggests that formation of the pseudo-dimer could arise from a 1,3dipolar cycloaddition of the initial dipole with a thioketone. However, further experiment aided by computation demonstrated that the by- product is actually a dithiocarbamate, which is formed in a 1:1 ratio with respect to the pseudo-dimer. By taking into account all the reactivities, the most favored step is the addition of ground state oxygen $\left({ }^{3} \mathrm{O}_{2}\right)$ to the $\mathrm{C}=\mathrm{N}$ bond of the dipole. The analyses of both diradical singlet and triplet PESs show that the triplet state is always lower in energy until the system reaches the first intermediate. SACASSCF calculations indicate that the SOC constants are very low for the three critical points (singlet and triplet intermediates and the $M E C P$ ), pointing to a small coupling between the two PESs. Thus, the rate of the ISC should be depending on reaction dynamics involving the $\mathrm{N}-\mathrm{C}-\mathrm{O}-\mathrm{O}$ dihedral angle, which with only a turn of 6.4 - and hence just $0.15 \mathrm{kcal} \mathrm{mol}^{-1}$, allows the triplet state to reach the MECP and experience the nonadiabatic transition to the singlet surface. Prior to ring closure, the system losses the spin density and becomes in a pure singlet state until the reaction ends. The two possible ringopening channels of the adduct show that the most favored process involves the detected formation of a dithiocarbamate, along with a $\mathrm{S}$-oxide of the mesoionic dipole. The latter can react with an additional unit of the dipole through four different reaction pathways. Among these competitive processes, the most favored pathway is the one leading to the resulting pseudo-dimer and consistent with a complete diastereoselective transformation. It is important to highlight that two additional chiral versions of the starting dipole, bearing phenyl and isopropyl groups, give rise to enantiomerically pure pseudo-dimers without detectable racemization.

Despite the potentiality of this complex oxidation that paves the way to explore similar mechanisms in other reactive heterocycles; some minuses and limitations cannot be overlooked, as no attempt was made to fully characterize the structures of any persistent radicals present in this system. Future work should interrogate the persistency of the radical species generated and the electronic transitions between the two PESs through nonadiabatic reaction dynamic studies, which lie however beyond the present scope.

\section{Experimental Section}

\section{General methods and chemical syntheses}

Solvents and reagents were purchased from commercial suppliers and used without further purification. The identity of all compounds was confirmed by their elemental analyses, melting points, NMR and crystallographic data (SI). Optical rotations were measured using a $\mathrm{Na}$ lamp $([\alpha] \mathrm{D}$ values at $\lambda=589 \mathrm{~nm})$. Yields of the autoxidation reactions refer to initial dipoles as the limiting reactants.

\section{8-(2-Oxothiazolidin-3-carbonyl)-6,8-diphenyldihydro- $2 \mathrm{H}-6,8 \mathrm{a}-$} epithiothiazolo[2,3-c][1,4]thiazin-5(3H)-one (2). A solution of 2phenyl-5,6-dihydrothiazolo[2,3-b]thiazol-4-ium-3-olate (1) (0.1 g, $0.42 \mathrm{mmol})$ in dry $\mathrm{CH}_{2} \mathrm{Cl}_{2}(15 \mathrm{~mL})$ was kept at room temperature for 7 days. The solvent was then removed under reduced pressure and the resulting crude was washed with cold acetone until the disappearance of the yellow color of the solid ( $34 \%$ yield). The same protocol was repeated using a two-necked flask, where air was bubbled through the solvent for $1 \mathrm{~h}$ maintaining the initial concentration of $\mathbf{1}$. This solution was kept at room temperature for $23 \mathrm{~h}$, and then this cycle was repeated for five more times. Work-up as above afforded compound $\mathbf{2}$ ( $80 \%$ yield). The first protocol was 
repeated but using $3 \mathrm{~mL}$ of dry $\mathrm{CH}_{2} \mathrm{Cl}_{2}$. The heterogeneous mixture was stirred until the solution of 1 was complete, and the reaction was stored for 5 days. Work-up as above afforded compound 2 (84\% yield). Mp 239-240 ㅇ. IR (KBr) $\bar{u}_{\text {max }}: 3060,3043,2925,2872,1956$, $1883,1738,1717,1696,1677,1442,1361,1259,1361,1259,1184$, $1156,1131,1043,711,634,493,473 \mathrm{~cm}^{-1} .{ }^{1} \mathrm{H} \mathrm{NMR}\left(500 \mathrm{MHz}, \mathrm{CDCl}_{3}\right)$ : $\delta$ 7.63-7.62 (m, 2H), 7.46-7.36 (m, 8H), 4.41-4.36 (m, $1 \mathrm{H}), 4.32-4.26$ $(\mathrm{m}, 1 \mathrm{H}), 3.90-3.86(\mathrm{~m}, 1 \mathrm{H}), 3.41-3.35(\mathrm{~m}, 1 \mathrm{H}), 3.29-3.24(\mathrm{~m}, 2 \mathrm{H}), 3.05-$ $3.00(\mathrm{~m}, 1 \mathrm{H}), 2.49-2.46(\mathrm{~m}, 1 \mathrm{H}), 2.27-2.21(\mathrm{~m}, 1 \mathrm{H}) \mathrm{ppm} .{ }^{13} \mathrm{C}$ NMR $(125$ $\left.\mathrm{MHz}, \mathrm{CDCl}_{3}\right): \delta 171.1,170.9,170.6,132.1,130.5,129.4,128.9,128.6$, $128.4,126.4,92.0,84.8,73.4,47.7,46.1,32.1,25.2 \mathrm{ppm}$. HRMS $\mathrm{m} / \mathrm{z}$ : $(\mathrm{M}+\mathrm{Na})^{+}$calcd for $\mathrm{C}_{22} \mathrm{H}_{18} \mathrm{~N}_{2} \mathrm{O}_{3} \mathrm{NaS}_{4}, 509.0092$; found: 509.0080 .

1-Phenyl-2-(2-thioxothiazolidin-3-yl)ethane-1,2-dione (4). To a solution of $1(1.3 \mathrm{~g}, 5.4 \mathrm{mmol})$ in dry $\mathrm{CH}_{2} \mathrm{Cl}_{2}(20 \mathrm{~mL})$ was added dropwise a solution of $m$-CPBA $(1.03 \mathrm{~g}, 6 \mathrm{mmol})$ in dry $\mathrm{CH}_{2} \mathrm{Cl}_{2}(30 \mathrm{~mL})$ and stirred during $10 \mathrm{~h}$ at room temperature. The solution was diluted with $30 \mathrm{~mL}$ of dry $\mathrm{CH}_{2} \mathrm{Cl}_{2}$ and extracted with a $1 \mathrm{M} \mathrm{KOH}$ solution $(5 \times 30 \mathrm{~mL})$. The organic layer was dried over $\mathrm{MgSO}_{4}$ and the solvent was then removed under reduced pressure. The resulting crude was passed through a short silica gel [Merck $^{\circ} 60$ (400-230 mesh)] column using ethyl acetate:hexane $(1: 1 \mathrm{v} / \mathrm{v})$ as eluent. The solvent was removed appearing the title compound as a yellow oil (50\% yield). FT-IR (ATR mode) $\bar{U}_{\text {max }}: 3062,2931,2853,1726,1667$, $1595,1571,1493,1443,1335,1230,1186,1166,1068,1041,1001$, $923,852,815,741,701 \mathrm{~cm}^{-1} .{ }^{1} \mathrm{H}$ NMR $\left(500 \mathrm{MHz}, \mathrm{CDCl}_{3}\right): \delta 7.86(\mathrm{~d}, J$ $=7.0 \mathrm{~Hz}, 2 \mathrm{H}), 7.60(\mathrm{t}, J=7.5 \mathrm{~Hz}, 1 \mathrm{H}), 7.49(\mathrm{t}, J=7.5 \mathrm{~Hz}, 2 \mathrm{H}), 4.61(\mathrm{t}, J$ $=7.5 \mathrm{~Hz}, 2 \mathrm{H}), 3.61(\mathrm{t}, J=7.5 \mathrm{~Hz}, 2 \mathrm{H}) \mathrm{ppm} .{ }^{13} \mathrm{C} \mathrm{NMR}\left(125 \mathrm{MHz}, \mathrm{CDCl}_{3}\right)$ : $\delta$ 200.9, 186.3, 167.1, 133.9, 133.7, 129.5, 128.8, 53.0, 30.8 ppm. HRMS $\mathrm{m} / \mathrm{z}:(\mathrm{M}+\mathrm{H})^{+}$calcd for $\mathrm{C}_{11} \mathrm{H}_{10} \mathrm{NO}_{2} \mathrm{~S}_{2}, 252.0153$; found: 252.0147 .

Reaction assays between 1 and 4 . In all cases the molar ratio between 1 and $\mathbf{4}$ was 1:1.1 and no reaction took place according to the following protocols: a) A solution of $\mathbf{1}$ and $\mathbf{4}$ in dry $\mathrm{CH}_{2} \mathrm{Cl}_{2}$ was monitored by TLC analysis for $24 \mathrm{~h}$ without indicating the appearance of compound 2. b) The same protocol repeated at reflux, either in $\mathrm{CH}_{2} \mathrm{Cl}_{2}$ or toluene, was unsuccessful as well. c) A suspension of 1 and 4 in toluene was heated in a professional microwave oven (Milestone-Ethos Touch Control MW reactor) using a non-sealed flask (at $300 \mathrm{~W}$ ) for 8 min until reaching a plateau of $100 \stackrel{\circ}{ } \mathrm{C}$, and then it was kept at that temperature for $12 \mathrm{~min}$ (three cycles).

(3S,6S,8R,8aS)-3-Isopropyl-8-((S)-2-oxothiazolidin-3-carbonyl)-6,8diphenyldihydro-2H-6,8a-epithiothiazolo[2,3-c][1,4]thiazin-5(3H)one (7). A solution of $5(0.15 \mathrm{~g}, 0.54 \mathrm{mmol})$ in dry $\mathrm{CH}_{2} \mathrm{Cl}_{2}(3 \mathrm{~mL})$ was kept at room temperature for 5 days. The solvent was removed under reduced pressure and diethyl ether was added to the reaction crude forming a residue, which was dissolved in warm acetone. The solution was kept at room temperature until the crystallization of compound 10 (60\% yield) occurred. Mp 223-225 ㅇ. $[\alpha]_{D}+532.3 \circ$ (c 4.9, $\mathrm{CH}_{2} \mathrm{Cl}_{2}$ ). ATR-IR $\bar{u}_{\text {max }}$ : 2958, 2927, 2893, 2868, 1705, 1676, 1464, $1446,1327,1242,1177,1159,1154,1082,940,816,717,689,640$, $537,485 \mathrm{~cm}^{-1} .{ }^{1} \mathrm{H}$ NMR $\left(500 \mathrm{MHz}, \mathrm{CDCl}_{3}\right): \delta 8.00-7.97(\mathrm{~m}, 1 \mathrm{H}), 7.67-$ $7.66(\mathrm{~m}, 2 \mathrm{H}), 7.45-7.38(\mathrm{~m}, 5 \mathrm{H})$ 7.35-7.32 (m, 2H), 4.90-4.87 (m, 1H), 3.47 (dd, $J=8.5 \mathrm{~Hz}, J=8.5 \mathrm{~Hz}, 1 \mathrm{H}), 3.20-3.17(\mathrm{~m}, 1 \mathrm{H}), 3.03(\mathrm{dd}, J=1$ $\mathrm{Hz}, J=11.5 \mathrm{~Hz}, 1 \mathrm{H}), 2.82-2.76(\mathrm{~m}, 1 \mathrm{H}), 2.60(\mathrm{dd}, J=3.5 \mathrm{~Hz}, J=11.5$ $\mathrm{Hz}, 1 \mathrm{H}) 2.39-2.29(\mathrm{~m}, 1 \mathrm{H}), 1.65(\mathrm{dd}, J=7.5 \mathrm{~Hz}, J=11.0 \mathrm{~Hz}, 1 \mathrm{H}), 1.04$ $(\mathrm{dd}, J=7.0 \mathrm{~Hz}, J=12 \mathrm{~Hz}, 6 \mathrm{H}), 0.80(\mathrm{~d}, J=6.5 \mathrm{~Hz}, 3 \mathrm{H}), 0.72(\mathrm{~d}, J=7.0$ $\mathrm{Hz}, 3 \mathrm{H}) \mathrm{ppm} .{ }^{13} \mathrm{C} \mathrm{NMR}\left(125 \mathrm{MHz}, \mathrm{CDCl}_{3}\right): \delta 171.5,170.6,169.4,132.8$, $131.3,129.2$, 129.0, 128.9, 128.4, 128.3, 127.9, 127.6, 127.5, 93.8, 84.6, 75.6, 65.2, 62.9, 32.4, 30.7, 27.3, 26.8, 19.6, 18.8, 17.8, 15.9 ppm. HRMS $\mathrm{m} / \mathrm{z}$ : $(\mathrm{M}+\mathrm{Na})^{+}$calcd for $\mathrm{C}_{28} \mathrm{H}_{30} \mathrm{~N}_{2} \mathrm{O}_{3} \mathrm{NaS}_{4}, 593.1031$; found, 593.1022.

\section{(R)-2,5-Diphenyl-5,6-dihydrothiazolo[2,3-b]thiazol-4-ium-3-olate}

(6). In following previous procedures, ${ }^{[11 a, b]}$ the title compound was obtained as an orange solid (58\% yield). Mp 194-196 ㄷ. $[\alpha]_{\mathrm{D}}+807.4$ 을 (c $6.5, \mathrm{CH}_{2} \mathrm{Cl}_{2}$ ). ATR-IR $\bar{u}_{\text {max }}$ : 3057, 3025, 1604, 1578, 1488, 1350, 1230, 1172, 1132, 1067, 748, 640, $560 \mathrm{~cm}^{-1} .{ }^{1} \mathrm{H}$ NMR $(500 \mathrm{MHz}$, $\left.\mathrm{CDCl}_{3}\right): \delta 7.72(\mathrm{~d}, J=7.5 \mathrm{~Hz}, 2 \mathrm{H}), 7.35-7.24(\mathrm{~m}, 7 \mathrm{H}), 7.03(\mathrm{t}, \mathrm{J}=7 \mathrm{~Hz}$, $1 \mathrm{H}), 6.00(\mathrm{~d}, J=7.5 \mathrm{~Hz}, 1 \mathrm{H}), 4.57(\mathrm{dd}, J=9.0 \mathrm{~Hz}, J=11.5 \mathrm{~Hz}, 1 \mathrm{H}), 3.74$ $(\mathrm{dd}, J=1.5 \mathrm{~Hz}, J=11.0 \mathrm{~Hz}, 1 \mathrm{H}) \mathrm{ppm} .{ }^{13} \mathrm{C} \mathrm{NMR}\left(125 \mathrm{MHz}, \mathrm{CDCl}_{3}\right): \delta$ 155.8, 152.3, 136.0, 134.2, 129.1, 129.0, 128.5, 126.0, 124.0, 122.6, 97.4, 64.1, 45.0 ppm. HRMS $\mathrm{m} / \mathrm{z}$ : $(\mathrm{M}+\mathrm{H})^{+}$calcd for $\mathrm{C}_{17} \mathrm{H}_{14} \mathrm{NOS}_{2}$, 312.0517; found, 312.0514 .

(3R,6R,8S,8aR)-8-((R)-2-Oxo-4-phenylthiazolidine-3-carbonyl)3,6,8-triphenyldihydro-8H-6,8a-epithiothiazolo[2,3-c][1,4]- thiazin$5(6 \mathrm{H})$-one (8). A solution of $6(0.68 \mathrm{~g}, 2.2 \mathrm{mmol})$ in dry $\mathrm{CH}_{2} \mathrm{Cl}_{2}(10 \mathrm{~mL})$ was allowed to stand at room temperature for 5 days. The solvent was removed under reduced pressure and diethyl ether was added to the reaction crude. The mixture was filtered off and the solution was evaporated to dryness. Ethanol was added to the resulting residue and the mixture was heated at reflux for two minutes and then filtered off. This operation was repeated again obtaining 8 as white crystals (70\% yield). Mp 203-205 ㅇ. $[\alpha]_{D}+568.95 \circ$ (c 5.7, $\mathrm{CH}_{2} \mathrm{Cl}_{2}$ ). ATR-IR $\bar{u}_{\max }: 3048,3024,2939,1713,16.88,1670,1490$, $1441,1325,1290,1240,1145,1127,1022,937,922,842,796,753$, $726,694,652 . \mathrm{cm}^{-1} .{ }^{1} \mathrm{H}$ NMR $\left(500 \mathrm{MHz}, \mathrm{CDCl}_{3}\right): \delta 8.13-8.11(\mathrm{~m}, 1 \mathrm{H})$, 7.65-7.64 (m, 2H), 7.51-7.48 (m, 5H) 7.41-7.34 (m, 9H), 7.25-7.19 (m, $3 \mathrm{H}), 6.07(\mathrm{~d}, J=7.5 \mathrm{~Hz}, 1 \mathrm{H}), 4.45$ (dd, $J=1.5 \mathrm{~Hz}, J=7.5 \mathrm{~Hz}, 1 \mathrm{H}), 3.92$ (dd, $J=8.5 \mathrm{~Hz}, J=11.5 \mathrm{~Hz}, 1 \mathrm{H}), 3.11$ (dd, $J=1.5 \mathrm{~Hz}, J=11.0 \mathrm{~Hz}, 1 \mathrm{H}$ ), $2.44(\mathrm{dd}, J=1.5 \mathrm{~Hz}, J=11.0 \mathrm{~Hz}, 1 \mathrm{H}$ ), $1.90(\mathrm{dd}, J=8.0 \mathrm{~Hz}, J=11.5 \mathrm{~Hz}$, 1H) ppm. ${ }^{13} \mathrm{C}$ NMR $\left(125 \mathrm{MHz}, \mathrm{CDCl}_{3}\right): \delta 171.2,170.1,168.8,139.8$, $138.8,133.1,130.8,129.3,129.2,128.9,128.6,128.5,128.4,128.3$, $128.2,127.9,126.0,125.3,93.1,84.8,74.9,62.3,60.38,42.0,33.6$ ppm. HRMS $\mathrm{m} / \mathrm{z}$ : $(\mathrm{M}+\mathrm{H})^{+}$calcd for $\mathrm{C}_{34} \mathrm{H}_{27} \mathrm{~N}_{2} \mathrm{O}_{3} \mathrm{~S}_{4}, 639.0905$; found, 639.0874 .

\section{Computational details}

All calculations were carried out with the Gaussian 16 package. ${ }^{22}$ The choice of a given method is of paramount importance when dealing with simulations of singlet diradicals. Herein we have chosen the global-hybrid GGA functional B3LYP ${ }^{13}$ due to several arguments: (i) First, the size of the system forced us to employ a DFT method; (ii) Since we had to describe multi-reference systems, a hybrid functional was also the first choice as hybrid functionals work in general better in broken symmetry wavefunctions [BS-(U)DFT] than pure functionals. The former minimizes the self-interaction error (SIE) of the exchange-correlation functional and calculates better static correlation effects, which are instrumental in multi-reference systems. ${ }^{23}$ (iii) Unrestricted wavefunctions can describe spin polarization effects as they allow $\alpha$ and $\beta$ electrons to have different spatial distribution. However, they are not eigenfunctions of the total spin operator $\left\langle\hat{S}^{2}\right\rangle$, suffering from spin contamination of higher spin states. This contamination has negative consequences on energy and geometric results, especially in functionals with high percentages of Hartree-Fock (HF) exchange. Therefore, among the hybrid functionals, B3LYP provides a $20 \% \mathrm{HF}$ exchange and despite its deficiencies, spin contamination occurs at less extent than other methods. ${ }^{24}$ All optimizations were performed in open shell, ${ }^{25}$ including the Grimme's GD3BJ dispersion correction with BeckeJohnson damping ${ }^{14}$ and the Ahlrichs triple- $\zeta$ basis set def2-TZVP. ${ }^{15}$ All 
optimizations and single point energy calculations were carried out with inclusion of continuum solvation effects with the SMD method. ${ }^{16}$ The solvent chosen was $\mathrm{CH}_{2} \mathrm{Cl}_{2}$ in order to simulate the experimental results. Frequency calculations were conducted at $298.15 \mathrm{~K}$ at the previously mentioned level of theory. Saddle points and energy minima were characterized by one or none imaginary frequencies, respectively. For all the stationary points we checked the eigenvalues of the total spin operator $\left\langle\hat{S}^{2}\right\rangle$ without taking into account the spin annihilation diagnostic. For triplets we obtained values of $\left\langle S^{2}\right\rangle=2$, and 0 for pure singlet states. For singlet-triplet mixtures, i. e. singlet diradicals, values very close to 1 were obtained. These results show that the computed wavefunctions are not (or almost) contaminated with higher spin states. Anyway, the stability of the wavefunction was always checked in order to locate the lowest energy solution of the SCF results and ensuring the system was in the ground state. When instabilities in singlet states were detected (singlet diradicals), the broken-symmetry wavefunctions [BS(U)B3LYP] were computed to destroy the $\alpha \beta$ spatial symmetries. Optimization of the minimum energy crossing point (MECP) was carried out using Harvey's method at the above-mentioned level of theory. ${ }^{18}$ This method considers that the two gradients vectors $f$ and $\boldsymbol{g}$ corresponding to the two PESs are orthogonal each other and become zero at the MECP. With the aim of validating the (U)DFT results for radical species, single point energies were computed with the complete active space self-consistent method (CASSCF), ${ }^{19}$ in combination with the above-mentioned triple- $\zeta$ basis set. The $\Delta \Delta E$ values found between singlet and triplet ( $\mathrm{TS1}_{\mathrm{C7a}}$, Int1 and MECP) were similar to those obtained with (U)DFT. Regarding the choice of the active space, we selected the orbitals involved in the reaction of mesoionic dipole 1 with molecular oxygen needed to reach the pure singlet peroxide Int2. Thus, the $\pi$ orbitals of the mesoionic ring, the two $\pi^{*}$, and the two $\pi$ of molecular oxygen were chosen, which gave a $(12,10)$ active space. The values of the diagonal of the density matrix for this active space led to high occupancies $(>1.98)$ of the two $\pi$ orbitals of molecular oxygen, being not available for excitations of other low-occupied orbitals and giving unreliable CAS results. Accordingly, these two orbitals were removed yielding a $(8,8)$ active space, which gave occupancies lower than 1.98 and higher than 0.02 . The selected active space does not supply relative energies with respect to the reactants, because the ground state of molecular oxygen has triplet multiplicity with two active orbitals giving only one configuration, making it impossible a CAS calculation. This limitation has been overcome by giving relative electronic energies between two states of the critical points TS1 $1_{\mathrm{C7a}}$, Int1, and MECP. Spin-orbit couplings (SOCS) between the triplet and singlet PESs were computed at the state-average $\operatorname{SA}-\operatorname{CASSCF}(8,8)$ where equal weights were given to the different states. The visualization of molecular orbitals was carried out using the Avogadro software. ${ }^{26}$ For the analysis of the alpha NBOs of the ${ }^{3} \mathrm{TS} 1_{\mathrm{C} 2}$ and ${ }^{3} \mathrm{TS} 1_{\mathrm{C7}}$ stationary points, the NBO 6.0 package ${ }^{27}$ was used and viewing the corresponding orbitals with the Jmol program. ${ }^{28}$

\section{Conflicts of interest}

There are no conflicts to declare.

\section{Acknowledgements}

We acknowledge the financial support from the Junta de Extremadura and FEDER (Fondo Europeo de Desarrollo Regional) through Grants GR18015 and IB16167. Computational assistance was provided by the Supercomputer facilities of LUSITANIA founded by Cénits and Computaex Foundation. This paper is also dedicated to the memory of both scientists and non-scientists died in Spain during the COVID-19 pandemic.

\section{Notes and references}

1. a) For a comprehensive treatment: E. T. Denisov, I. B. Afanas'ev, Oxidation and Antioxidants in Organic Chemistry and Biology, CRC Press, Inc., Boca Raton, FL, 2005. b) J. McMurry, T. Begley, The Organic Chemistry of Biological Pathways, Roberts \& Co. Publishers, Engelwood, CO, 2005, pp. 34-36, 148-153. c) P. M. Dewick, Medicinal Natural Products, $2^{\text {nd }} E d$., John Wiley \& Sons, Inc., New York, 2002, pp. 24-28. d) M. G. Smic, J. Chem. Educ., 1981, 58, 125-131.

2. a) A. Goosen and D. H. Morgan, J. Chem. Soc., Perkin Trans. 2 1994, 557-562. b) M. B. Smith and J. March, March's Advanced Organic Chemistry, $5^{\text {th }} E d$., John Wiley \& Sons, Inc., New York, 2001, pp. 920-924.

3. G. W. Gribble, Mesoionic Ring Systems. In Synthetic Applications of 1,3-Dipolar Cycloaddition Chemistry Toward Heterocycles and Natural Products (Eds: A. Padwa and W. H. Pearson), John Wiley and Sons, Inc., New York, 2002, pp 681753.

4. M. Ávalos, R. Babiano, P. Cintas, J. L. Jiménez and J. C Palacios, Acc. Chem. Res. 2005, 38, 460-468.

5. J. M. Lopchuk, Mesoionics. In Metalation of Azoles and Related Five-Membered Ring Heterocycles (Ed: G. W. Gribble), Springer, Berlin, 2012, pp 381-413.

6. J. García de la Concepción, R. F. Martínez, P. Cintas and J. L. Jiménez, Cycloadditions with Mesoionic Dipoles: Strategy and Control. In Targets in Heterocyclic Systems, Vol. 21 (Eds: O. Attanasi, P. Merino and D. Spinelli), Italian Society of Chemistry, Rome, Italy, 2018, Ch. 11, pp 228-253.

7. For a recent and timely overview: E. Decuypère, L. Plougastel, D. Audisio and F. Taran, Chem. Commun., 2017, 53, 1151511527.

8. M. K. Narayanam, Y. Liang, K. N. Houk and J. M. Murphy, Chem. Sci., 2016, 7, 1257-1261.

9. J. García de la Concepción, M. Ávalos, P. Cintas and J. L. Jiménez, Chem. Eur. J., 2018, 24, 7507-7512.

10. a) R. Huisgen, I. Kalvinsch, X. Li and G. Mloston, Eur. J. Org. Chem., 2000, 1685-1694. b) I. Kalwinsch, X. Li, J. Gottstein and R. Huisgen, J. Am. Chem. Soc., 1981, 103, 7032-7033. c) G. Mloston, J. Romanski, E. B. Rusanov, A. N. Tshernega, and Y. G. Shermolovich, Russ. J. Org. Chem., 1995, 31, 952-955. (d) M. Kägi, A. Linden, H. Heimgartner and G. Mloston, Helv. Chim. Acta, 1993, 76, 1715-1728.

11. H. Kato, K. Tani, H. Kurumisawa and Y. Tamura, Heterocycles, 1987, 26, 1313-1322. 
12. a) J. García de la Concepción, M Ávalos, R. Babiano, P. Cintas, J. L. Jiménez, M. E. Light and J. C. Palacios, Tetrahedron, 2016, 72, 4665-4670. b) J. García de la Concepción, M Ávalos, R. Babiano, P. Cintas, J. L. Jiménez, M. E. Light and J. C. Palacios, Tetrahedron, 2017, 73, 1551-1560. c) J. García de la Concepción, M Ávalos, P. Cintas, J. L. Jiménez and M. E. Light, Org. Biomol. Chem., 2018, 16, 3438-3452

13. a) A. D. Becke, J. Chem. Phys., 1993, 98, 5648-5652. b) C. Lee, W. Yang and R. G. Parr, Phys. Rev. B: Condens. Matter Mater. Phys., 1988, 37, 785-789. (c) B. Miehlich, A. Savin, H. Stoll and H. Preuss, Chem. Phys. Lett., 1989, 157, 200-206.

14. a) S. Grimme, J. Antony, S. Ehrlich and H. Krieg, J. Chem. Phys., 2010, 132, 154104. b) S. Grimme, S. Ehrlich and L. Goerigk, J. Comp. Chem., 2011, 32, 1456-1465.

15. a) F. Weigend, Phys. Chem. Chem. Phys. 2006, 8, 1057-1065. b) F. Weigend and R. Ahlrichs, Phys. Chem. Chem. Phys., 2005, 7, 3297-3305

16. a) A. V. Marenich, C. J. Cramer and D. G. Truhlar, J. Phys. Chem. B, 2009, 113, 4538-4543. b) A. V. Marenich, C. J. Cramer and D. G. Truhlar, J. Phys. Chem. B, 2009, 113, 6378-6396. c) R. F. Ribeiro, A. V. Marenich, C. J. Cramer and D. G. Truhlar, J. Comput.-Aided Mol. Des., 2010, 24, 317-333. d) M. A. Halim, D. M. Shaw and R. A. Poirier, J. Mol. Struct. (THEOCHEM), 2010, 960, 63-72. e) G. Saielli, J. Phys. Chem. A 2010, 114 7261-7265.

17. a) K. Wolinski, J. F. Hilton and P. Pulay, J. Am. Chem. Soc., 1990, 112, 8251-8260. b) J. R. Cheeseman, G. W. Trucks, T. A. Keith and M. J. Frisch, J. Chem. Phys., 1996, 104, 5497-509.

18. a) J. N. Harvey, M. Aschi, H. Schwarz and W. Koch, Theor. Chem. Acc., 1998, 99, 95-99. b) R. Poli and J. N. Harvey, Chem. Soc. Rev., 2003, 32, 1-8.

19. a) B. Roos, Adv. Chem. Phys., 1987, 69, 399-445. b) J. L. Calais, O. Goscinski, J. Linderberg and Y. Öhrn, Quantum Science, Plenum Press, New York, 1976, p. 505. c) M. W. Schmidt and M. S. Gordon, Annu. Rev. Phys. Chem., 1998, 49, 233-266.

20. H. Li, A. Kamasah, S. Matsika and A. G. Suits, Nat. Chem., 2019, 11, $123-128$

21. K. Park, A. West, E. Raheja, B. Sellner, H. Lischka, T. L. Windus and W. L. Hase, J. Chem. Phys., 2010, 133, 184306.

22. M. J. Frisch, G. W. Trucks, H. B. Schlegel, G. E. Scuseria, M. A. Robb, J. R. Cheeseman, G. Scalmani, V. Barone, G. A Petersson, H. Nakatsuji, X. Li, M. Caricato, A. V. Marenich, J. Bloino, B. G. Janesko, R. Gomperts, B. Mennucci, H. P. Hratchian, J. V. Ortiz, A. F. Izmaylov, J. L. Sonnenberg, D. Williams-Young, F. Ding, F. Lipparini, F. Egidi, J. Goings, B. Peng, A. Petrone, T. Henderson, D. Ranasinghe, V. G. Zakrzewski, J. Gao, N. Rega, G. Zheng, W. Liang, M. Hada, M. Ehara, K. Toyota, R. Fukuda, J. Hasegawa, M. Ishida, T. Nakajima, Y. Honda, O. Kitao, H. Nakai, T. Vreven, K. Throssell, J. A. Montgomery, Jr., J. E. Peralta, F. Ogliaro, M. J. Bearpark, J. J. Heyd, E. N. Brothers, K. N. Kudin, V. N. Staroverov, T. A Keith, R. Kobayashi, J. Normand, K. Raghavachari, A. P. Rendell, J. C. Burant, S. S. Iyengar, J. Tomasi, M. Cossi, J. M. Millam, M. Klene, C. Adamo, R. Cammi, J. W. Ochterski, R. L.
Martin, K. Morokuma, O. Farkas, J. B. Foresma and D. J. Fox, Gaussian 16, Revision A.03, Gaussian, Inc., Wallingford, CT, 2016.

23. J. Gräfenstein, E. Kraka, M. Filatov and D. Cremer, Int. J. Mol. Sci., 2002, 3,360-394.

24. a) A. S. Menon. and L. Radom, J. Phys. Chem. A, 2008, 112, 13225-13230. b) D. López-Carballeira and F. Ruipérez, J Mol. Model., 2016, 22, 76.

25. T. Bally and W. T. Borden, Calculations on Open-Shell Molecules: A Beginner' Guide. In Reviews in Computational Chemistry (Eds.: K. B. Lipkowitz and D. B. Boyd), John Wiley \& Sons, Inc., Hoboken, NJ, 1999, Vol. 3, pp. 1-97.

26. M. D. Hanwell, D. E. Curtis, D. C. Lonie, T. Vandermeerrsch, E. Zurek and G. R. Hutchison, J. Cheminformatics, 2012, 4, 17.

27. E. D. Glendening, J. K. Badenhoop, A. E. Reed, J. E. Carpenter, J. A. Bohmann, C. M. Morales, C. R. Landis and F. Weinhold, Theoretical Chemistry Institute, University of Wisconsin, Madison, 2013.

28. http://www.jmol.org/. 